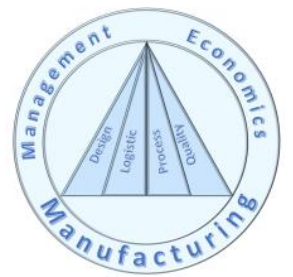

\title{
CHOOSING THE OPTIMUM TECHNOLOGICAL ALTERNATIVE FOR 3D PRINTING
}

\author{
Daniel Mindru ${ }^{1}$, Constantin Carausu ${ }^{2}$ \\ ${ }^{1}$ S.C. NECOM S.R.L., Sos. Nicolina, nr. 165, Iasi, Romania \\ 2 "Gheorghe Asachi" Technical University of Iasi-Romania, Department of Machine \\ Manufacturing Technology, Blvd. Mangeron 59A, 700050, Iasi, Romania
}

Corresponding author: Constantin Cărăușu, constantin.carausu@academic.tuiasi.ro

\begin{abstract}
The period between the design of a product and the moment from which the product is no longer profitable on the market represents its life cycle. Decreasing the profitability of the product on the market means that the company must find solutions to launch a new product. The new products can be assimilated in the manufacture by own conception at the level of the enterprise, on the basis of the purchased manufacturing licenses and on the basis of the reference models of a similar product existing on the market. The paper presents the methodology for choosing the optimal technological variant for a part manufactured by $3 \mathrm{D}$ printing using two technological variants, through the criterion of unit technological cost and the criterion of total technological cost. Depending on the relationship between the size of the manufacturing batch and the calculated critical size of the manufacturing batch, respectively between the unit technological cost and the total technological cost for the two technological variants, the optimal technological variant of manufacturing can be established.
\end{abstract}

Keywords: 3D printing, unit technological cost, total technological cost, optimal technological alternative

\section{INTRODUCTION}

According to the total product model developed by Kotler and Armstrong (1994), the product, in general, can be characterized by its projections in the conceptual plan, the material plan and the service plan. Thus, in the conceptual plan are presented the characteristics of the product and its utilities on the market, all these materializing in the material plan that characterizes the product by brand name, packaging, quality, etc. A number of additional services, if they can be offered, are part of the service plan, [1]. Any change in the characteristics of a product can generate a new product, the process of manufacturing and launching new products being a vital one for the growth or even survival of an enterprise on the market.

The development of new products begins with the determination of the need that the new product must satisfy and ends with the launch of the product on the market. Suggestively, figure 1 shows the phases of the new product development process. 

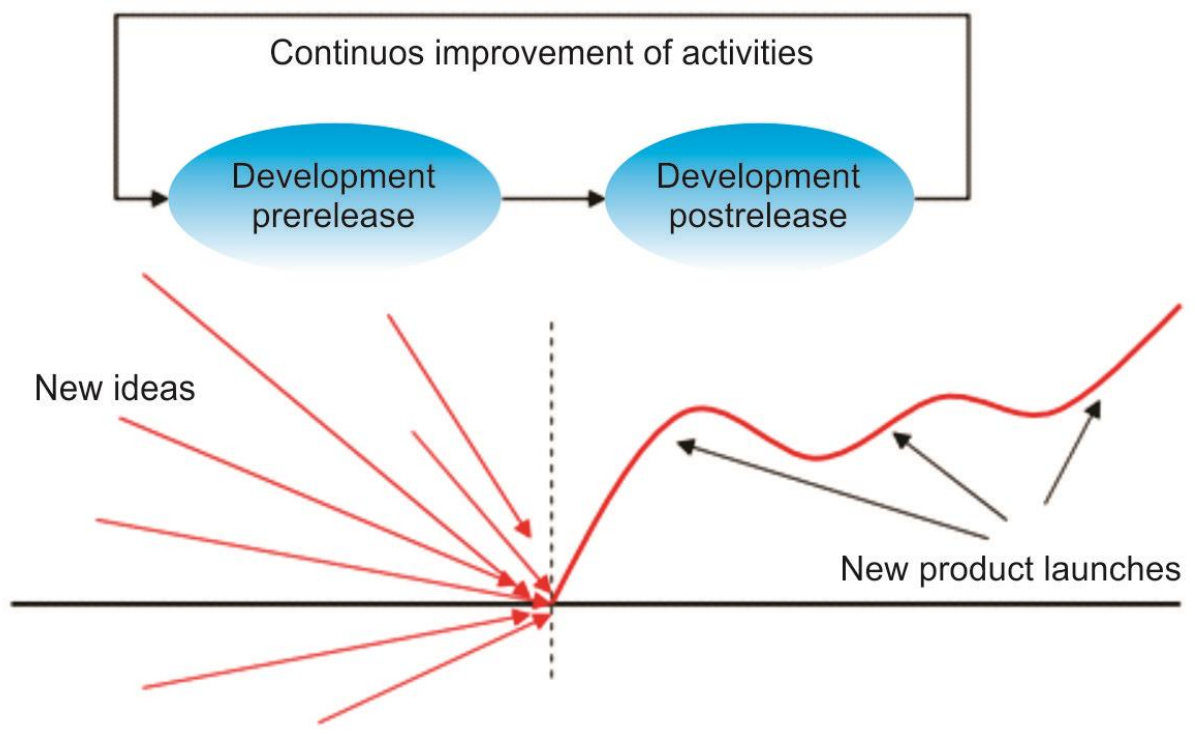

Fig.1. Steps of the new product development process, [2]

The pre-launch phase is up to 5 years and involves teams of specialists in the field, and the post-launch phase has a period of approximately 10-15 years and involves the entire enterprise. The separation between the two phases represents the optimal moment of launching the new product on the market.

In other words, according to [3], the steps for launching a new product on the market refer to determining the requirements for the new product, generating new product ideas and evaluating these ideas, economic justification of the new product, testing the market and the decision or not to trade being stages prior to the actual manufacture of the new product.

The product life cycle represents the period between its design and the moment when the product is no longer profitable on the market, when the market is saturated and it is necessary to launch a new product on the market, figure 2 . In this figure the areas have the following meaning: I-market study; II-development; III-launch; IV-growth; V-maturity; VI-decline. Moreover, the design of the product is the sum of the first two periods, I and II, the life or manufacturing curve and the distribution represent the sum between zones III, IV, V and VI, and the life cycle of the product is the sum of all seven zones.

Of course, as you go through all the stages presented, there may be factors that can negatively influence the launch of new products on the market, such as: incorrect market analysis, much higher costs than anticipated, incorrect determination of the launch time of the new product on the market, insufficient activities of the marketing department, and a deficient analysis of the competition. Therefore, it is especially important that these factors be analyzed initially and, moreover, that the success factors of launching a product on the market be developed, such as: adapting the product to real needs, the new product to incorporate modern manufacturing technologies, the product should be supported by the management of the enterprise, and the competitive environment should be favorable, $[5$, 6]. 


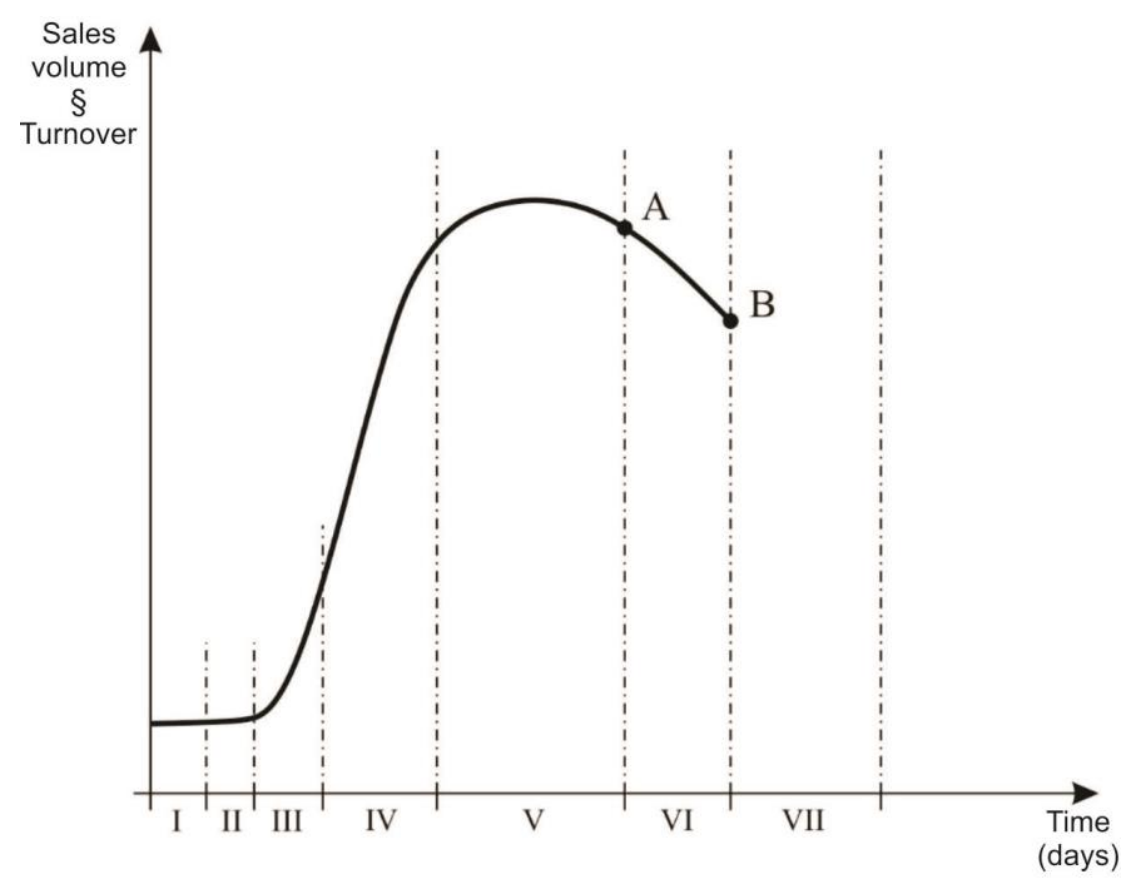

Fig.2. Product life cycle, (adaptation after [4]): I-market study; II-development; IIIlaunch; IV-growth; V-maturity; VI-decline; VII-elimination of the product

\section{CHOOSING THE OPTIMUM TECHNOLOGICAL ALTERNATIVE FOR 3D PRINTING}

The research of the marketing department of a company that also uses modern manufacturing technologies by $3 \mathrm{D}$ printing, by analyzing the variation of the sales share on the market, showed that one of the products registers in the last two years significant decreases regarding the sales share. The information transmitted to the superior management structures determined the decisions to replace this product with one with clearly superior performance that responds exactly to the demands on the market. In turn, receiving the request to analyze from the point of view of manufacture, the corresponding department of the company specified that the new proposed product, based on a rigorous market foundation, can be executed in two technological variants, Fused Deposition Modeling-FDM and Stereolithography-SLS, each having the advantages / disadvantages presented in table 1 .

Also, the manufacturing department specified the number of parts in the batch, namely in batches of 5, 10, 20 and 40 pieces, and the financial accounting department communicated the levels of expenses, presented in table 2 . The choice of the optimal option will be it is based on the unit technological cost and on the total technological cost, each of which can be solved analytically and graphically. 
Table 1. Characterization of the proposed 3D printing methods, [7-10]

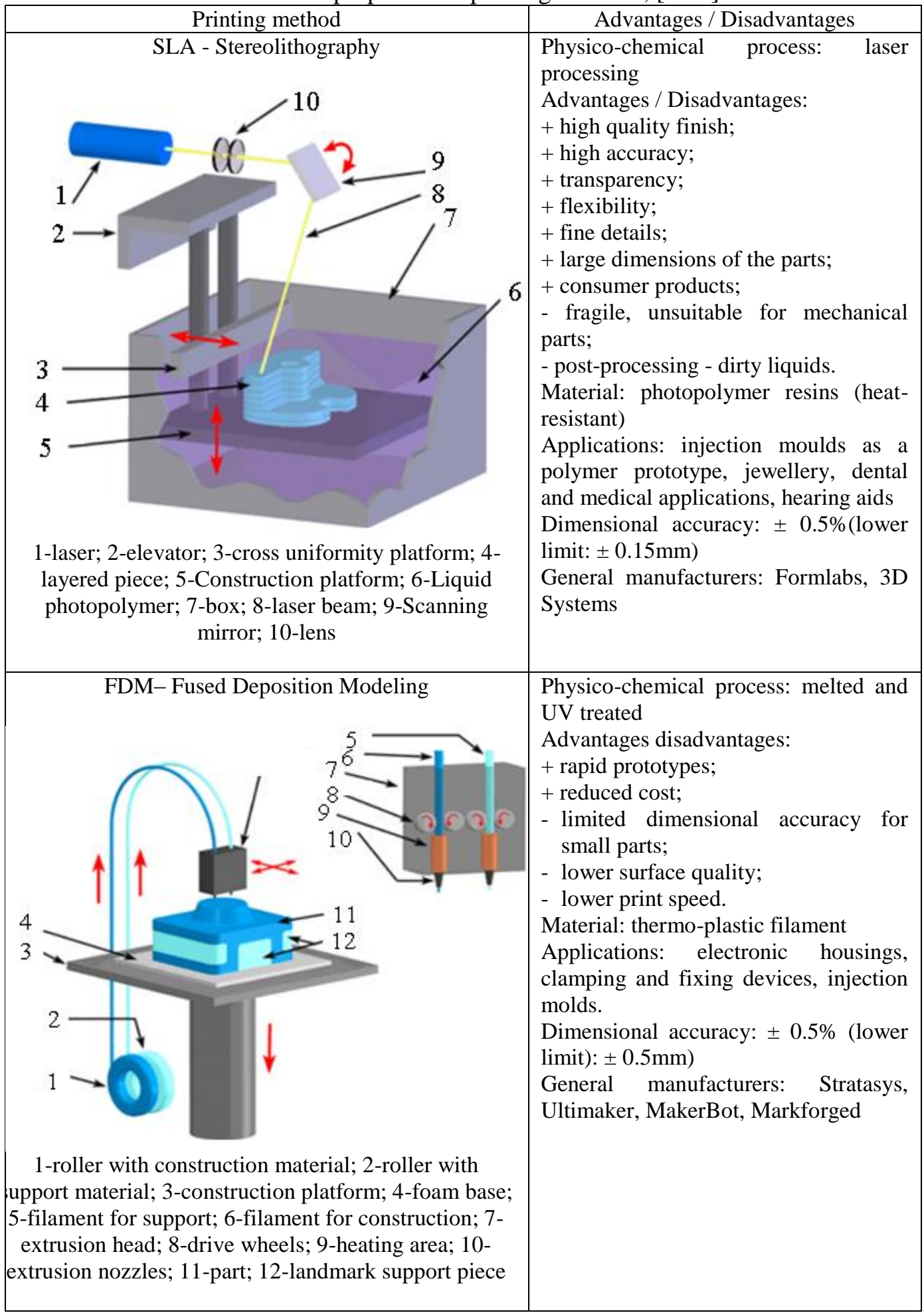


Table 2. Expenditure levels for the new product

\begin{tabular}{|c|c|c|}
\hline Parameter & Technological variant I & Technological variant II \\
\hline $\begin{array}{c}\text { Variable expenses }\left(\mathrm{C}_{\mathrm{V}}\right), \\
{\left[\mathrm{UV}^{*}\right]}\end{array}$ & $\mathrm{C}_{\mathrm{v} 1}=13000$ & $\mathrm{C}_{\mathrm{v} 2}=11000$ \\
\hline $\begin{array}{c}\text { Conventional-constant } \\
\text { expenses }\left(\mathrm{C}_{\mathrm{c}}\right),[\mathrm{UV}]\end{array}$ & $\mathrm{C}_{\mathrm{c} 1}=140000$ & $\mathrm{C}_{\mathrm{c} 2}=180000$ \\
\hline
\end{tabular}

* value units

\subsection{Choosing the optimal variant according to the unit technological cost}

As previously mentioned, both the criterion based on the unit technological cost and the total technological cost, there are two solutions of approach, analytical and graphical.

Table 3 presents the specific calculations for the two analytical manufacturing variants.

Table 3. The analytical solution at the unit technological cost

\begin{tabular}{|c|c|c|c|c|c|c|}
\hline \multirow{3}{*}{$\begin{array}{c}\text { Batch } \\
\text { size } \\
(\mathrm{N})\end{array}$} & \multicolumn{4}{|c|}{ Technological variant I } & \multicolumn{3}{c|}{ Technological variant II } \\
\cline { 2 - 7 } & $\mathrm{C}_{\mathrm{v} 1}$, & $\mathrm{C}_{\mathrm{c} 1} / \mathrm{N}$ & $\mathrm{C}_{\mathrm{Tu} 1}=\mathrm{C}_{\mathrm{v} 1}+$ & $\mathrm{C}_{\mathrm{v} 2}$, & $\mathrm{C}_{\mathrm{c} 2} / \mathrm{N}$ & $\mathrm{C}_{\mathrm{Tu} 2}=\mathrm{C}_{\mathrm{v} 2}+$ \\
{$[\mathrm{UV}]$} & {$[\mathrm{UV}]$} & $\mathrm{C}_{\mathrm{c} 1} / \mathrm{N},[\mathrm{UV}]$ & {$[\mathrm{UV}]$} & {$[\mathrm{UV}]$} & $\mathrm{C}_{\mathrm{c} 2} / \mathrm{N}[\mathrm{UV}]$ \\
\hline 5 & 13000 & 28000 & 41000 & 11000 & 36000 & 47000 \\
\hline 10 & 13000 & 14000 & 27000 & 11000 & 18000 & 29000 \\
\hline 20 & 13000 & 7000 & 20000 & 11000 & 9000 & 20000 \\
\hline 40 & 13000 & 3500 & 16500 & 11000 & 4500 & 15500 \\
\hline
\end{tabular}

In the case of the analytical approach, the size of the critical quantity is calculated using relation (1), resulting in a manufacturing batch of 20 products for which the unit technological costs are equal, so any technological variant of manufacturing can be adopted.

$\mathbf{N}_{\mathbf{c r}}=\frac{\mathbf{C}_{c 2}-\mathbf{C}_{c 1}}{C_{v 1}-C_{v 2}}=\frac{180000-140000}{13000-11000}=20$

Figure 3 shows the graphic solution for choosing the manufacturing technological variant according to the unit technological cost. The critical batch size is found at the intersection of unit technology cost curves, $\mathrm{C}_{\mathrm{Tu} 1}$ și $\mathrm{C}_{\mathrm{Tu} 2}$.

For lots $(\mathrm{N})$ whose size is greater than the size of the calculated critical quantity $\left(\mathrm{N}_{\mathrm{cr}}\right)$, unit cost for technological variant II $\left(\mathrm{C}_{\mathrm{Tu} 2}\right)$ is lower than the unit cost for technological variant $\mathrm{I}\left(\mathrm{C}_{\mathrm{Tu} 1}\right)$; in this case the technological variant II is optimal.

For lots $(\mathrm{N})$ whose size is smaller than the size of the calculated critical quantity $\left(\mathrm{N}_{\mathrm{cr}}\right)$, unit cost for technological variant $\mathrm{I}\left(\mathrm{C}_{\mathrm{Tu} 1}\right)$ is higher than the unit cost for technological variant II $\left(\mathrm{C}_{\mathrm{Tu} 2}\right)$; technological variant $\mathrm{I}$ is optimal. 


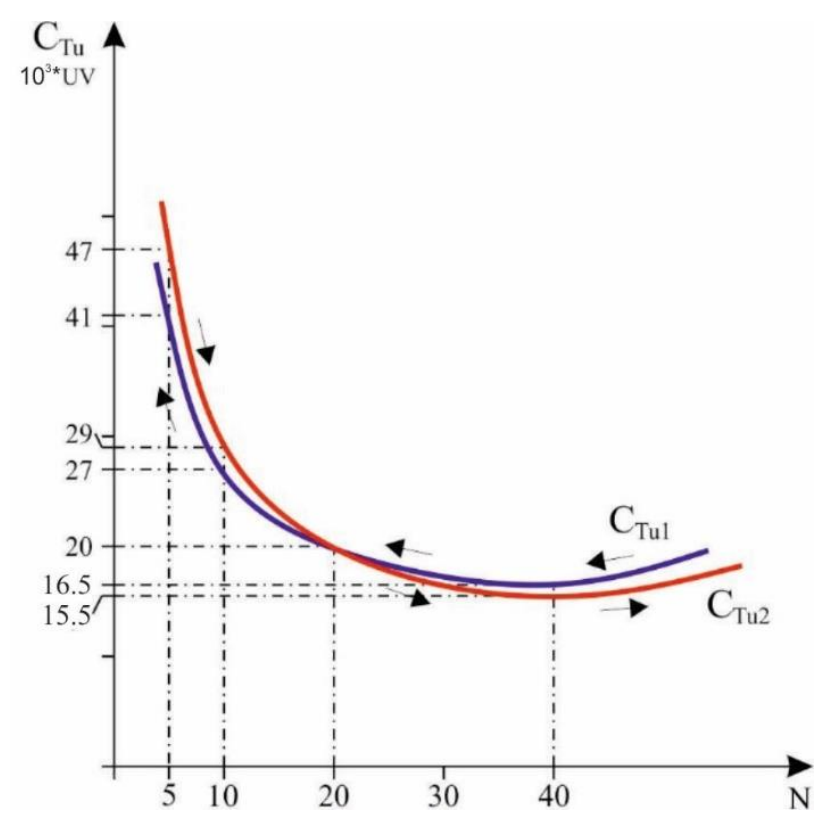

Fig. 3. Graphic method for determining the optimal variant using the unit technological cost criterion

\subsection{Choosing the optimal variant according to the total technological cost}

In this variant, the calculations made for the total technological cost are presented in table 4.

Table 4. The analytical solution at the total technological cost

\begin{tabular}{|c|r|r|r|r|r|r|}
\hline \multirow{3}{*}{ Batch size } & \multicolumn{3}{|c|}{ Technological variant I } & \multicolumn{3}{|c|}{ Technological variant II } \\
\cline { 2 - 7 } & $\begin{array}{c}\mathrm{C}_{\mathrm{c} 1}, \\
{[\mathrm{UV}]}\end{array}$ & $\begin{array}{c}\mathrm{C}_{\mathrm{v} 1} \cdot \mathrm{N} \\
{[\mathrm{UV}]}\end{array}$ & $\begin{array}{r}\mathrm{C}_{\mathrm{Tt} 1}=\mathrm{C}_{\mathrm{v} 1} \cdot \mathrm{N}+ \\
\mathrm{C}_{\mathrm{c} 1}[\mathrm{UV}]\end{array}$ & $\begin{array}{l}\mathrm{C}_{\mathrm{c} 2} \\
{[\mathrm{UV}]}\end{array}$ & $\begin{array}{c}\mathrm{C}_{\mathrm{v} 2} \cdot \mathrm{N} \\
{[\mathrm{UV}]}\end{array}$ & $\begin{array}{c}\mathrm{C}_{\mathrm{Tt} 2}=\mathrm{C}_{\mathrm{v} 2} \cdot \mathrm{N}+ \\
\mathrm{C}_{\mathrm{c} 2} \\
{[\mathrm{UV}]}\end{array}$ \\
\hline 5 & 140000 & 65000 & 205000 & 180000 & 55000 & 235000 \\
\hline 10 & 140000 & 130000 & 270000 & 180000 & 110000 & 290000 \\
\hline 20 & 140000 & 260000 & 400000 & 180000 & 220000 & 400000 \\
\hline 40 & 140000 & 520000 & 660000 & 180000 & 440000 & 620000 \\
\hline
\end{tabular}

Using the relation (1) the size of the critical quantity, the same number of 20 products is obtained, because the total technological costs of the two variants are equal to $400000 \mathrm{UV}$. The graphic solution is presented in figure 2 for the case of using the criterion of total technological cost.

And when using the total technological cost, the following comments can be made.

If the size of the batch $(\mathrm{N})$ is larger than the size of the calculated critical quantity $\left(\mathrm{N}_{\mathrm{cr}}\right)$ and the total cost for technological variant $\mathrm{I}\left(\mathrm{C}_{\mathrm{Tt} 1}\right)$ is higher than the total cost for technological variant II $\left(\mathrm{C}_{\mathrm{T} t 2}\right)$ then the technological variant I is chosen as optimal. 
If the size of the batch $(\mathrm{N})$ is less than the size of the calculated critical quantity $\left(\mathrm{N}_{\mathrm{cr}}\right)$ and the total cost for the technological variant II $\left(\mathrm{C}_{\mathrm{T} t 2}\right)$ is lower than the total cost for technological variant $\mathrm{I}\left(\mathrm{C}_{\mathrm{Tt1}}\right)$ then the technological variant II is chosen as optimal.

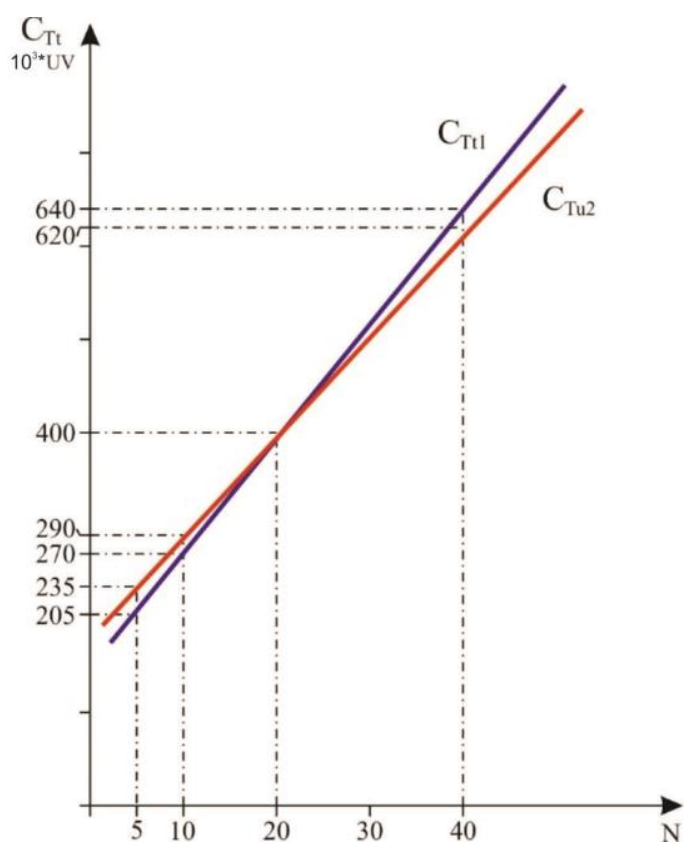

Fig. 4. Graphic method for determining the optimal variant using the criterion of total technological cost

\section{CONCLUSIONS}

At some point in the life cycle of a product on the market, it registers a sharp decrease in profitability, which means that the launch of a new product can be a necessary solution for the continuity in profitable conditions of the company's activity. Own design, the acquisition of manufacturing licenses and the adoption of similar product models can be real solutions for assimilating a new product into manufacturing. Considering two possible manufacturing technologies for a new product, two criteria were used, the technological unit cost and the total technological cost, for the optimal technological variant. Moreover, the choice was based on the calculation of the critical size of the manufacturing batch and depending on the size of the proposed manufacturing batch and the interdependence between the two costs taken into account, the optimal technological variant of manufacturing was chosen.

\section{REFERENCES}

1. Kotler P., Armstrong G., (1994), Principles of marketing, Englewood Cliffs, N.J. : Prentice-Hall.

2. https://pdfcoffee.com/lansarea-produselor-noi-pdf-free.html

3. Ulrich K., (2011), Product Design and Development, $5^{\text {th }}$ Edition, McGraw-Hill.

4. https://pdfcoffee.com/ciclul-de-viata-al-produsului-2-pdf-free.html

5. https://www.rasfoiesc.com/business/management/managementul-activitatii-de-as12.php 
6. https://www.scribd.com/document/134892577/Managementul-pregatirii-fabricatiei 7. Mazurchevici A-D., Nedelcu D., (2020), Contributii la studiul procesului de printare $3 \mathrm{D}$ a materialelor biodegradabile, Editura PIM, Iasi.

8. Mazurchevici A-D, Carausu C., Ciofu C., Popa R., Mazurchevici S-N, Nedelcu D., (2019), Infill and Type Influence on Tensile Strength of PLA Biodegradable Material using FDM Technology, International Journal of Modern Manufacturing Technologies 11 (2), 44-49.

9. Nedelcu D., Mazurchevici A-D., (2021), Calorimetry, Structure and Morphology of Printed Samples from Biodegradable Materials Using FDM 3D Printing Technology, Fused Deposition Modeling Based 3D Printing, 43-61, Springer.

10. Mazurchevici, A-D., Nedelcu, D., Popa R., (2021), Additive manufacturing of composite materials by FDM technology: A review, Indian Journal of Engineering and Materials Sciences (IJEMS), 27 (2), 179-192.

Received: June 28, 2021 / Accepted: December 15, 2021 / Paper available online: December 20, 2021 (C) International Journal of Manufacturing Economics and Management. 